\title{
3D Indoor Building Environment Reconstruction using Least Square Adjustment, Polynomial Kernel, Interval Analysis and Homotopy Continuation
}

\author{
Ali Jamali ${ }^{1}$, François Anton ${ }^{2}$, Alias Abdul Rahman ${ }^{1}$ and Darka Mioc ${ }^{2}$ \\ 1) Universiti Teknologi Malaysia(UTM) \\ Faculty of Geoinformation and Real Estate \\ ali.jamali.65@gmail.com, \\ alias@utm.my \\ 2) Technical University of Denmark, Denmark \\ National Space Institute, \\ francescantoncastro@me.com,mioc@live.com
}

KEY WORDS : Indoor surveying, least square adjustment, interval analy sis, laser scanning, calibration, homotopy continuation

\begin{abstract}
:
Nowadays, municipalities intend to have 3D city models for facility management, disaster management and architectural planning. Indoor models can be reconstructed from construction plans but sometimes, they are not available or very often, they differ from 'as-built' plans. In this case, the buildings and their rooms must be surveyed. One of the most utilized methods of indoor survey ing is laser scanning. The laser scanning method allows taking accurate and detailed measurements. However, Terrestrial Laser Scanner is costly and time consuming. In this paper, several techniques for indoor 3D building data acquisition have been investigated. For reducing the time and cost of indoor building data acquisition process, the Trimble LaserAce 1000 range finder is us ed. The proposed approache use relatively cheap equipment: a light Laser Rangefinder which appear to be feasible, but it needs to be tested to see if the observation accuracy is sufficient for the 3D building modelling. The accuracy of the rangefinder is evaluated and a simple spatial model is reconstructed from real data. This technique is rapid (it requires a shorter time as compared to others), but the results show inconsistencies in horizontal angles for short distances in indoor environments. The range finder horizontal angle sensor was calibrated using a least square adjustment algorithm, a polynomial kernel, interval analy sis and homotopy continuation.
\end{abstract}

\section{Introduction}

The automatic reconstruction of urban 3D models has been a research area of photogrammetry for the past two decades (Haala and Kada, 2010). According to Habib et al. (2010), digital 3D modelling of complex buildings has been a challenge until now with photogrammetry technology. This leads towards semi-automated construction of complex 3D building models. Difficulties of interpretation of photogrammetric images for 3D city modelling, especially for complex buildings, motivated increasing demands for 3D point cloud technologies such as LiDAR (light detection and ranging), which can facilitate automated $3 \mathrm{D}$ building models.

According to Surmann et al. (2003), rapid characterization and quantification of complex environments with increasing demands has created a challenge for 3D data analysis. This crucial demand comes from different fields such as industrial automation, architecture, agriculture, construction and mine and tunnel maintenance. Precise 3D data is needed for facility management, factory design and regional and urban planning. Considering all the issues affecting fully automated construction of complex 3D building models, 3D indoor modelling is another aspect in the field of $3 \mathrm{D}$ city modelling which can make the current situation more complex. According to Deak et al. (2012), indoor location determination has become a crucial aspect in many different applications but unfortunately, a lack of standard is one of the challenges and there are more challenges encountered in this field. According to Donath and Thurow (2007), considering many fields of applications for building surveying and resulting different demands, representation of the building geometry is the most crucial aspect of a building survey. Due to the complexity of indoor environment, this field needs to be more researched.

Recently, there has been more interest for $3 \mathrm{D}$ building modeling based on LiDAR data, but extracting buildings from huge LiDAR datasets is difficult and time consuming and requires experienced technicians. Laser scanning technology started in the 1990s (Amato et al., 2003) and it can measure a 3D object surface with a high speed pulse. This technology is considered as a tool for remote and rapid data collection and it can be used in many different applications from urban and regional planning to architecture. A scanner can directly measure distance and reflection intensity of 3D object surfaces and automatically store collected data in a spatial database. Recent TLS 
technology can collect more than 500,000 points in a second with an accuracy of $\pm 6 \mathrm{~mm}$ (Dongzhen et al., 2009).

In this research, we provide a comparative analysis of $3 \mathrm{D}$ reconstruction and indoor survey of a building done using the Leica scanstation $\mathrm{C} 10$ and the Trimble LaserAce 1000 rangefinder (see Figure 1). The Trimble LaserAce 1000 has been used for outdoor mapping and measurements, such as forestry measurement and GIS mapping (Jamali et al., 2013). A rangefinder can be considered as a basic mobile Total Station with limited functionality and low accuracy. The Trimble LaserAce 1000 is a three-dimensional laser rangefinder with point and shoot workflow. This rangefinder includes a pulsed laser distance meter and a compass, which can measure distance, horizontal angle and vertical angle up to 150 meter without a target and up to 600 meter with a reflective foil target. In this research, we propose this device for indoor mapping and try to validate this technique in an indoor environment. Trimble LaserAce 1000 will decrease time and cost of surveying process (Jamali et al. 2015).

a)

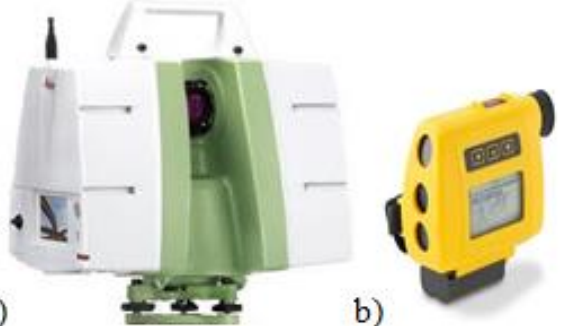

Figure 1: Surveying devices: a) Leica scanstation C10 b) Trimble LaserAce 1000

Following this introduction, in Section 2, the requirements of indoor building surveying are discussed. In Section 3, the range finder is calibrated using a least square adjustment algorithm. In section 4, the rangefinder is calibrated using a polynomial kernel. In Section 5, the range finder is calibrated using interval analysis and homotopy continuation in order to control the uncertainty of the calibration and of the reconstruction of the building. Section 6 presents conclusions and future research.

\section{REQUIREMENTS OF AN INDOOR BUILDING SURVEYING METHOD}

In this research, the survey or according to his experience and knowledge defined several requirements for indoor building surveying as follows:

\section{i. Number of control points and their positions}

To get better results with less shape deformation (e.g. intersection and gap between two rooms due to low accuracy of Trimble LaserAce 1000), for each door, there should be a control point inside the corridor. For example, if a room has two doors, there should be two control points in the corridor to access that certain room by its two doors (see Figure 2).

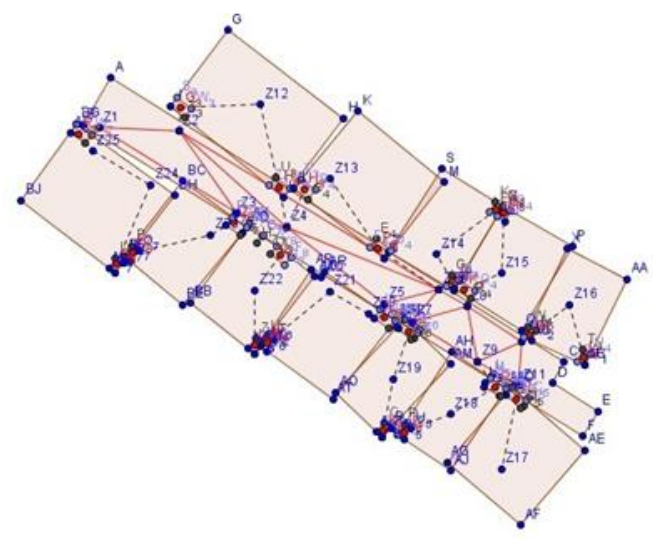

Figure 2: Position of control points by Trimble LaserAce 1000

To avoid narrow and wide angle propagation which will lead to shape deformation, Trimble LaserAce 1000 needs to be stationed in the center of each room. In reality, there will be some furniture in rooms which avoids putting Trimble LaserAce 1000 in the center of a room. Thus, for a fully furnished room, there should be at least two control points.

\section{i. Number of repetitions of measurements}

Based on the surveyor's skills, for a certain distance and angle measurement, there should be at least three observations. Trimble LaserAce 1000 shows inconsistency in horizontal angle in an indoor building environment. By increasing number of repetitions for a measurement, the probability of a mistake or blunder occurring will be decreased. In this paper, we use least squares adjustment as a statistical method and interval analysis and homotopy continuation as mathematical methods to calibrate our low accuracy surveying equipment in an indoor building environment. Thus, a higher number of measurements will led to a more accurate average using least square adjustment and more accurate measurement intervals using interval analy sis and homotopy continuation.

\section{ii. Time}

Time is one of the most important factors in this research. The cost of a surveying project will be decreased by reducing the time of data collection. There should be a balance between the number of repetitions and the time to collect data of a room. The time for collecting data of a room with three repetitions (horizontal angle, vertical distance, horizontal distance and vertical distance) and one control point using Trimble LaserAce 1000 is between 5 to 10 minutes based on our experiments. As seen in Figure 3, Trimble LaserAce 1000 is handy and easy to use, which can decrease the time of data collection. Based on the survey or experience, Rangefinder is 2 times quicker compared to a traditional Total Station (e.g. Leica 307 TCR) and 10 times quicker compared to a terrestrial laser scanner (e.g. Leica Scan Station C10). 


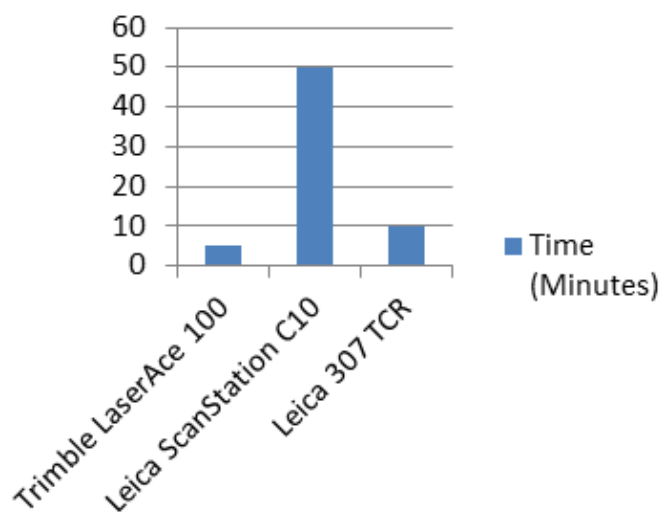

Figure 3: Time of data collection and 3D building modeling

$$
\text { i. Cost }
$$

The cost of the rangefinder is very low compared to the other devices (laser scanner and Total Station) used in this research (See Figure 4).

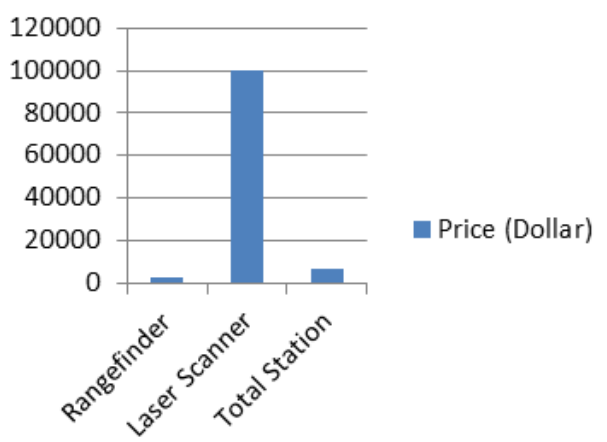

Figure 4: Equipment comparison based on the cost.

\section{i. Data storage}

Data storage for a floor collected by Trimble LaserAce 1000 with twelve rooms and one corridor is around 10 Kilo Bytes $(\mathrm{KB})$ in Object model (.obj) data format, $14 \mathrm{~KB}$ in Geogebra data format without control points and $38 \mathrm{~KB}$ with control points. Data collected by Leica scanstation C10 occupies 4.18 Giga Bytes (GB). Data collected using Leica scanstation $\mathrm{C} 10$ contains unnecessary details such as furniture and installations. Data storage, rendering and modeling need to be considered as important factors in most of applications. Navigation through a building (Yuan and Schneider 2010; Li and He 2008; Goetz and Zipf 2011) is possible by nodes and lines (paths or edges) and 3D building models allow a better understanding of the real world environment.

\section{RANGEFINDER CALIBRATION}

Coordinates measured by rangefinder are not as precise as laser scanner or total station measurements. As seen in Figures 5 and 6, results of Trimble LaserAce 1000 shows deformation of building geometry.

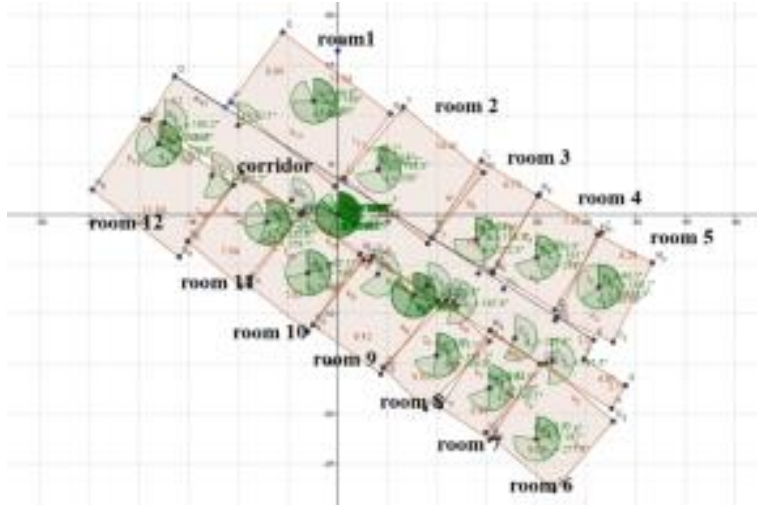

Figure 5: Floor plan by Trimble LaserAce 1000.

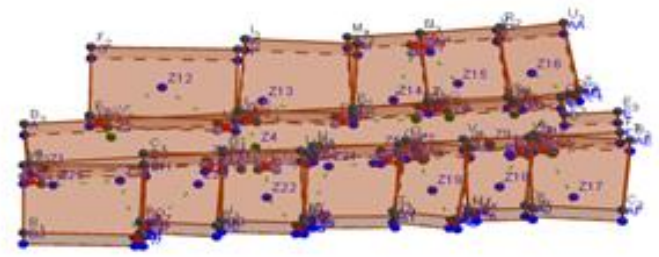

Figure 6: 3D building modelling of room 9 by Trimble LaserAce 1000 where dash lines represent measured data from Trimble LaserAce 1000 and solid lines represent extruded floor plan.

Figure 7 shows a 3D point cloud collected by Leica scanstation $\mathrm{C} 10$.

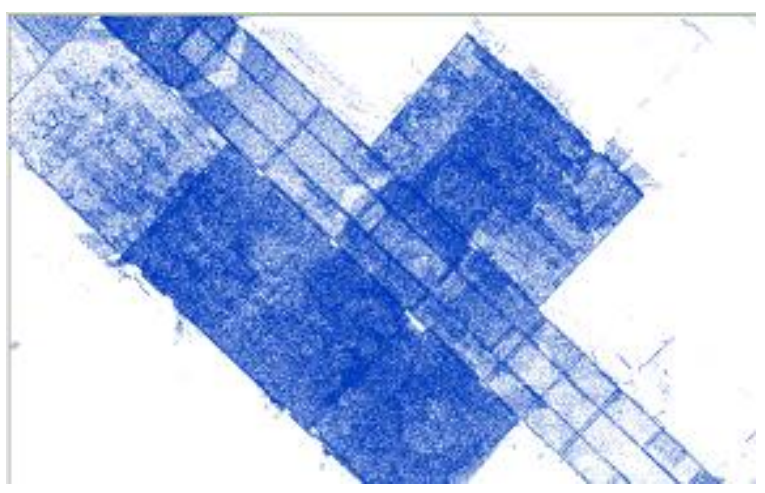

Figure 7: point cloud data collected by Leica scanstation $\mathrm{C} 10$

According to device specifications, the accuracies of the Leica scanstation C10, Trimble LaserAce 1000 are as shown in Table 1.

Table 1: Accuracies according to product specifications. 


\begin{tabular}{|l|l|l|l|}
\hline $\begin{array}{l}\text { Surveying } \\
\text { Equipment }\end{array}$ & $\begin{array}{l}\text { Distance } \\
\text { Accuracy }\end{array}$ & $\begin{array}{l}\text { Horizontal } \\
\text { Angle } \\
\text { Accuracy }\end{array}$ & $\begin{array}{l}\text { Vertical } \\
\text { Angle } \\
\text { Accuracy }\end{array}$ \\
\hline $\begin{array}{l}\text { Leica } \\
\text { scanstation } \\
\text { C10 }\end{array}$ & $\pm 4 \mathrm{~mm}$ & $12 "$ & $12 "$ \\
\hline $\begin{array}{l}\text { Trimble } \\
\text { LaserAce } \\
\mathbf{1 0 0 0}\end{array}$ & $\pm 100 \mathrm{~mm}$ & $7200 "$ & $720 "$ \\
\hline
\end{tabular}

The 3D building measured by the Trimble LaserAce 1000 can be calibrated and reconstructed from the Leica scanstation $\mathrm{C} 10$ based on the least square adjustment algorithm, in the form of absolute orientation. Least square adjustment is a well-known algorithm in surveying engineering which is used widely by engineers to get the best solution in the sense of the minimization of the sum of the squares of the residuals, which is obtained as in the following normal equations, which express that the total differential of the sum of squares of residuals is zero. Least square adjustment for a linear system is shown in Equation (1).

$X=\left(A^{\mathrm{T}} \mathrm{WA}\right)^{-1} \mathrm{~A}^{\mathrm{T}} \mathrm{W} \mathrm{L}$

$\mathrm{X}=\mathrm{N}^{-1} \mathrm{~A}^{\mathrm{T}} \mathrm{W} \mathrm{L}$

Where $\mathrm{L}=$ observations

$\mathrm{X}=$ unknowns

$\mathrm{A}=$ coefficient of unknowns

$\mathrm{W}=$ observation's weight

$\mathrm{N}=\left(\mathrm{A}^{\mathrm{T}} \mathrm{W} A\right)$

Considering two points, $\mathrm{Pa}=(\mathrm{XA}, \mathrm{YA}, \mathrm{ZA})$ from the Leica $\mathrm{C} 10$ and $\mathrm{Pc}=(\mathrm{XC}, \mathrm{YC}, \mathrm{ZC})$ from the Trimble LaserAce 1000 , the absolute orientation problem can be defined as the transformation between two coordinates systems (Leica C10 and Trimble LaserAce 1000). The relationship between measuring devices can be solved by using absolute orientation. Absolute orientation can be found by a set of conjugate pairs: $\{(\mathrm{Pc}, 1, \mathrm{~Pa}, 1),(\mathrm{Pc}, 2 \mathrm{~Pa}, 2), \ldots,(\mathrm{Pc}, \mathrm{n}, \mathrm{Pa}, \mathrm{n})\}$. For a pair of common points in both (camera coordinates and absolute coordinates) sy stems; rotation, scale and translation components can be calculated by Equations 2 to 4, where the matrix R with coefficients RXX, RXY, RXZ, RYX, RYY, $\mathrm{RYZ}, \mathrm{RZX}, \mathrm{RZY}$ and RZZ, is the matrix of a linear transformation combining a $3 \mathrm{D}$ rotation (that can be decomposed into the combinations of 3 rotations along the $\mathrm{x}, \mathrm{y}$ and $\mathrm{z}$ axes) and a scaling, and its determinant is the scaling parameter (since the determinant of a rotation matrix must equal 1).

$X A=R X X X C+R X Y Y C+R X Z Z C+T X$

$\mathrm{YA}=\mathrm{RYXXC}+\mathrm{RYY} Y \mathrm{YC}+\mathrm{RYZZC}+\mathrm{TY}$

$Z A=R Z X X C+R Z Y Y C+R Z Z Z C+T Z$

Twelve unknown parameters, including nine linear transformation (combined rotation and scaling) parameters and three translations components need to be solved. Each conjugate pair yields three equations. The minimum number of required points to solve for the absolute orientation is thus four common points. Practically, to get better results with higher accuracy, a higher number of points need to be used. The coordinates of the points measured by the rangefinder can be adjusted, or their maximum error can be minimized, by adjusting the coefficients of the rotation matrix $R$ and the translation vector (see adjustment results in Table 2). Room number nine has been selected by the researcher to calculate its absolute orientation parameters.

Table 2: Coefficient of unknowns including rotation, scale and translation parameters (matrix A).

\begin{tabular}{|l|l|l|l|l|}
\hline $\mathbf{R}$ & $\begin{array}{l}\mathbf{X} \\
\text { coefficien } \\
\mathbf{t}\end{array}$ & $\begin{array}{l}\mathbf{Y} \\
\text { coefficien } \\
\mathbf{t}\end{array}$ & $\begin{array}{l}\mathbf{Z} \\
\text { coefficien } \\
\mathbf{t}\end{array}$ & $\begin{array}{l}\text { Translatio } \\
\mathbf{n} \\
\text { coefficient }\end{array}$ \\
\hline $\mathbf{X}$ & -0.6929 & -0.6793 & -1.6964 & 2.8987 \\
\hline $\mathbf{Y}$ & 0.6850 & -0.6981 & 3.3957 & -5.8893 \\
\hline $\mathbf{Z}$ & 0.0003 & -0.0000 & 0.0453 & 1.0590 \\
\hline
\end{tabular}

Absolute orientation can be found by computing the rotation matrix $R$ and the translation vector for any given point. Any points measured by the rangefinder can be transferred or absolutely oriented by using the corresponding matrix A arrays. Results from calibrating the Trimble LaserAce 1000 based on the least square adjustment (Absolute orientation) using the Leica C10 data were calculated (see Table 3). 
Table 3: LaserAce 1000 calibration based on the least square adjustment (Absolute orientation).

\begin{tabular}{|l|l|l|l|l|l|l|}
\hline $\begin{array}{l}\text { Point } \\
\text { Number }\end{array}$ & X LaserAce & Y LaserAce & Z LaserAce & X Leica C10 & Y Leica C10 & Z Leica C10 \\
\hline $\mathbf{1}$ & 10.394 & 3.7777 & 1.1067 & 10.424 & 3.725 & 1.105 \\
\hline $\mathbf{2}$ & 2.0673 & 2.3577 & 1.1122 & 2.131 & 2.249 & 1.109 \\
\hline $\mathbf{3}$ & 2.0098 & 3.2969 & 1.1098 & 1.956 & 3.355 & 1.109 \\
\hline $\mathbf{4}$ & 1.4469 & 3.1347 & 1.1094 & 1.396 & 3.257 & 1.116 \\
\hline $\mathbf{5}$ & 0.0059 & 10.678 & 1.11 & 0.047 & 10.605 & 1.108 \\
\hline $\mathbf{6}$ & 8.8322 & 12.192 & 1.1128 & 8.803 & 12.246 & 1.115 \\
\hline
\end{tabular}

Considering the Leica C10 data as absolute coordinates, differences between two coordinates can be referred as the Trimble LaserAce 1000 accuracy. The model calibrated and reconstructed using the Leica $\mathrm{C} 10$ is shown in Figure. 8. Model in black lines represents model reconstructed from raw data of Trimble LaserAce 1000 and model in blue lines represents model reconstructed from Leica C10. Calibrated model of Trimble LaserAce 1000 based on the least square adjustment algorithm from Leica $\mathrm{C} 10$ data can be seen as red dash line model (see Figure 8).

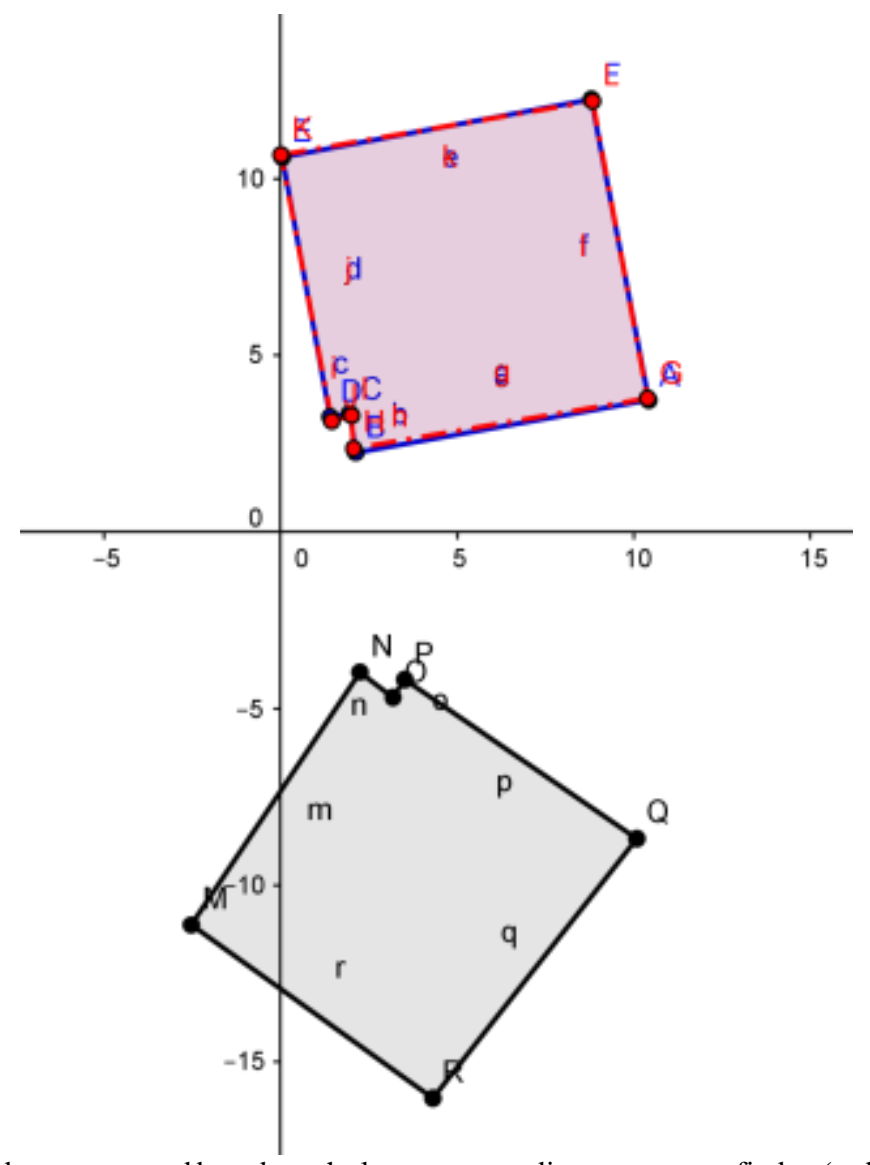

Figure 8: Model calibrated and reconstructed based on the least square adjustment; rangefinder (red dash lines), total station (blue lines) and non-calibrated rangefinder (black lines).

\section{POLYNOMIAL KERNEL}

In this section, polynomial kernel as a non-parametric nonlinear method is used to calibrate Trimble LaserAce 1000 horizontal angle. In kernel methods, data is embedded into a vector space and then linear and non-linear relations between data will be investigated. Basically, kernels are functions that return inner products between of the images of data points in vector space. Each kernel $\mathrm{k}(\mathrm{x}, \mathrm{z})$ has an associated feature mapping $\varphi$ which takes input $\mathrm{x} \in \mathrm{X}$ (input space) and maps it to $\mathrm{F}$ (feature space). Kernel $\mathrm{k}(\mathrm{x}, \mathrm{z})$, takes two inputs and gives their similarity in $\mathrm{F}$ space $(\varphi=X \rightarrow F k=$ $\left.X \times X \rightarrow R \quad k(x, z)=\varphi(x)^{T} \varphi(z)\right)$. 
F needs to be a vector space with a dot product to define it, also called a Hilbert space (Browder and Petryshyn, 1967; Akhiezer and Glazman, 2013). For k to be a kernel function, a Hilbert space $\mathrm{F}$ must exist and $\mathrm{k}$ must define a dot product and be positive definite $\left(\int d x \int d z f(x) k(x, z) f(z)>0\right)$.

There are several kernel function including linear kernel $\left(k(x, z)=x^{T} z\right)$, quadratic kernel $\left(\mathrm{k}(\mathrm{x}, \mathrm{z})=\left(\mathrm{x}^{T} \mathrm{z}\right)^{2}\right)$, polynomial kernel $\left(\mathrm{k}(\mathrm{x}, \mathrm{z})=\left(\mathrm{x}^{T} \mathrm{z}\right)^{d}\right)$ and Radial Basis Function $(\mathrm{RBF})$ kernel $\left(k(x, z)=\exp \left[-\gamma\|x-z\|^{2}\right]\right)$.
In this section, we use polynomial kernel to find similarities between the rangefinder horizontal angles and the total station horizontal angles and then, to use calculated parameters to calibrate the rangefinder horizontal angles. Table 7 represents results of calibrated horizontal angle of Trimble LaserAce 1000 using different degrees of polynomial kernel, while Table 5 represents the analog results for room 10 using least square parameters calculated for room 1. As seen in Table 5, these results are not satisfactory. 
Table 4: Calibration of room 1 rangefinder horizontal angle measurements using total station horizontal angle measurements by polynomial kernels.

\begin{tabular}{|l|l|l|l|l|l|}
\hline Point & $\begin{array}{l}\text { Horizontal angle } \\
\text { rangefinder }\end{array}$ & $\begin{array}{l}\text { Horizontal } \\
\text { angle } \\
\text { theodolite }\end{array}$ & $\begin{array}{l}\text { Calibrated rangefinder } \\
\text { horizontal } \\
\text { (degree=1) }\end{array}$ & $\begin{array}{l}\text { Calibrated } \\
\text { angle } \\
\text { angefinder horizontal } \\
\text { angle }\end{array}$ & $\begin{array}{l}\text { Calibrated rangefinder } \\
\text { horizontal angle } \\
\text { (degree=3) }\end{array}$ \\
\hline 1 & 268.9 & 0 & 84.5 & 88.995 & 0.03656 \\
\hline 2 & 336.0 & 67.745139 & 33.906 & 29.145 & 67.734 \\
\hline 3 & 99.6 & 190.595419 & 212.16 & 209.66 & 193.08 \\
\hline 4 & 166.1 & 256.477086 & 162.01 & 167.45 & 256.38 \\
\hline 5 & 98.5 & 190.741669 & 212.98 & 210.31 & 188.32 \\
\hline
\end{tabular}

Table 5: Calibration of room 10 rangefinder horizontal angle measurements using total station horizontal angle measurements by polynomial kernel calculated from room 1.

\begin{tabular}{|c|c|c|c|c|c|}
\hline Point & $\begin{array}{l}\text { Horizontal angle } \\
\text { rangefinder } \\
\text { (decimal } \\
\text { degrees) }\end{array}$ & $\begin{array}{l}\text { Horizontal angle } \\
\text { total station } \\
\text { (decimal degrees) }\end{array}$ & $\begin{array}{lr}\text { Calibrated rangefinder } \\
\text { horizontal } \\
\text { (polynomial } & \text { angle } \\
\text { degree }=1) & \text { kernel, }\end{array}$ & $\begin{array}{l}\text { Calibrated rangefinder } \\
\text { horizontal angle } \\
\text { (polynomial kernel, } \\
\text { degree=2) }\end{array}$ & $\begin{array}{l}\text { Calibrated rangefinder } \\
\text { horizontal angle } \\
\text { (polynomial kernel, } \\
\text { degree }=3 \text { ) }\end{array}$ \\
\hline 1 & 259.1 & 351 & 91.8897 & 97.1652 & 17.8313 \\
\hline 2 & 355 & 86.3 & 19.5796 & 10.9583 & 174.1801 \\
\hline 3 & 77.1 & 165.85 & 229.1206 & 222.4298 & 64.3471 \\
\hline 4 & 180 & 274.92 & 151.5324 & 157.7771 & 229.6545 \\
\hline
\end{tabular}

\section{INTERVAL ANALYSIS AND HOMOTOPY CONTINUATION}

Interval analysis is a well-known method for computing bounds of a function, being given bounds on the variables of that function (E. Ramon Moore and Cloud, 2009). The basic mathematical object in interval analysis is the interval instead of the variable. The operators need to be redefined to operate on intervals instead of real variables. This leads to an interval arithmetic. In the same way, most usual mathematical functions are redefined by an interval equivalent. Interval analysis allows one to certify computations on intervals by providing bounds on the results. The uncertainty of each measure can be represented using an interval defined either by a lower bound and a higher bound or a midpoint value and a radius.

In this paper, we use interval analysis to model the uncertainty of each measurement of horizontal angle and horizontal distance done by the range finder. We represent the geometric loci corresponding to each surveyed point as functions of the bounds of each measurement. Thus, for distances observed from a position of the range finder, we represent the possible position of the surveyed point by two concentric circles centered on the position of the range finder and of radii the measured distance plus and minus the uncertainty on the distance respectively (see Figure 9). For horizontal angles observed from a position of the range finder, we represent the possible position of the surveyed point by two rays emanating from the position of the range finder and whose angles with respect to a given point or the North are the measured angle plus and minus the uncertainty on the horizontal angle respectively (see Figure 9). Therefore, the surveyed point must be within a region bounded by these 4 loci: in between 2 concentric circles and 2 rays. Proceeding in the same way for each room, we get the geometric loci for each room and for the union of the survey ed rooms (see Figure 9).

A homotopy is a continuous deformation of geometric figures or paths or more generally functions: a function (or a path, or a geometric figure) is continuously deformed into another one (Allgower and Georg, 1990). The use of homotopies can be tracked back to works of Poincaré (18811886), Klein (1882-1883), and Berstein (1910) (Allgower and Georg, 1990). The use of homotopies to solve non-linear systems of equations may be traced back at least to Lahaye (1934) (Allgower and Georg, 1990). 


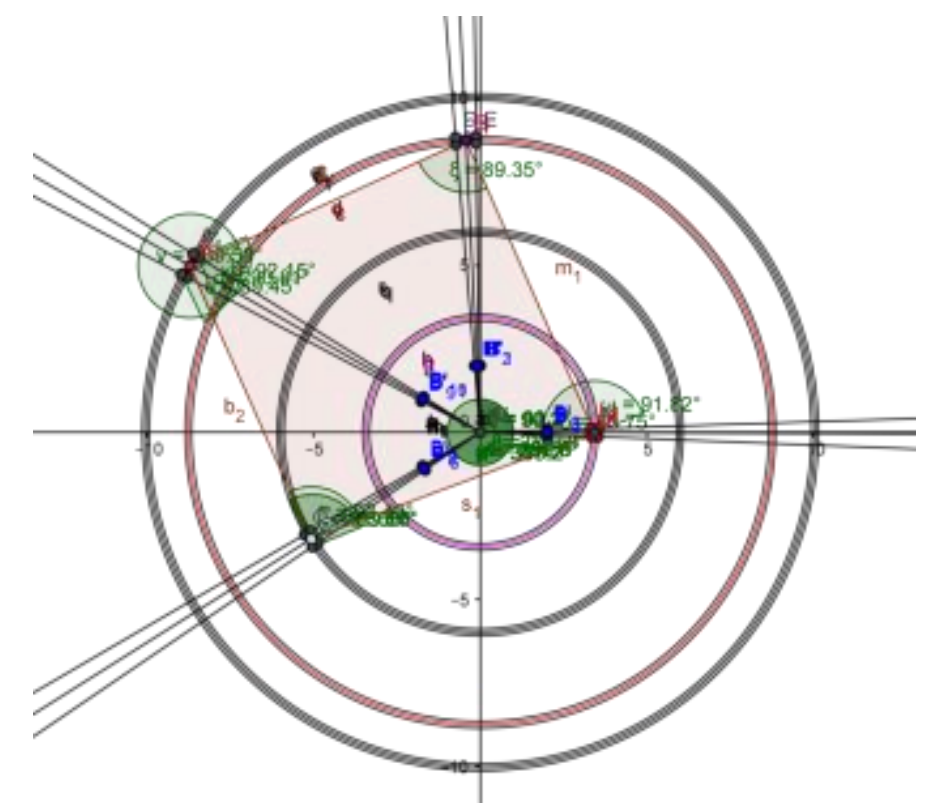

Figure 9: The geometric loci of each corner of a room as a function of all the measurements

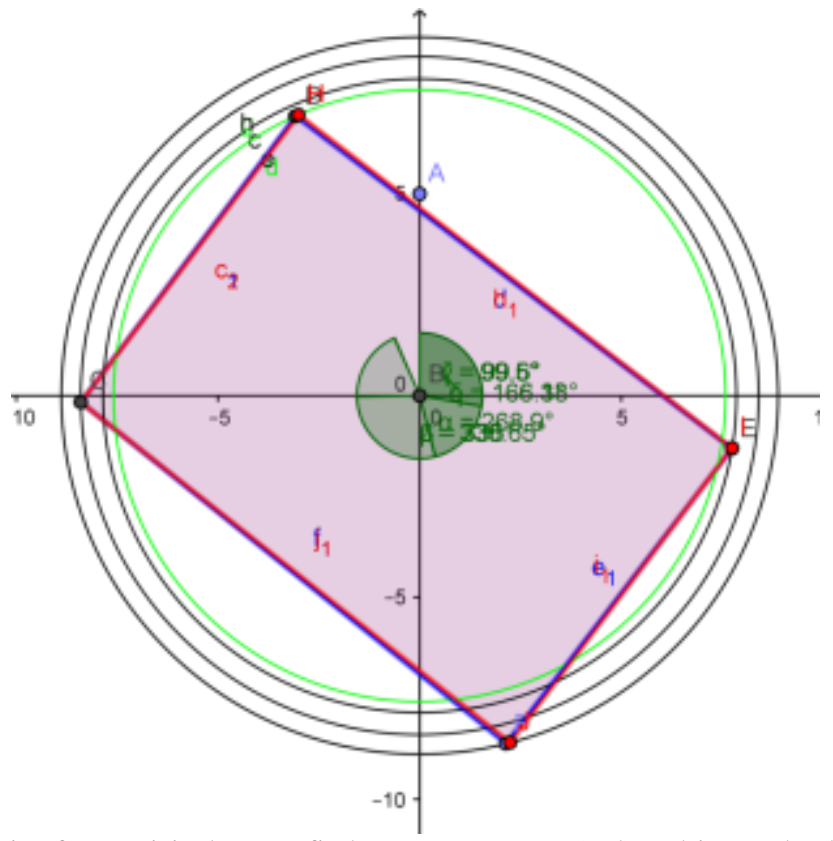

Figure 10: Room 1 construction from original range finder measurements (red) and interval valued homotopy continuation calibration of horizontal angles measurements (blue)

A homotopy between two continuous functions $\mathrm{f}$ and $\mathrm{f}$ from a topological space $\mathrm{X}$ to a topological space $\mathrm{Y}$ is defined as a continuous map $\mathrm{H}: \mathrm{X} \times[0,1] \rightarrow \mathrm{Y}$ from the Cartesian product of the topological space $\mathrm{X}$ with the unit interval $[0$, 1] to $Y$ such that $H(x, 0)=f 0$, and $H(x, 1)=f 1$, where $x \in$ $\mathrm{X}$. The two functions $\mathrm{f} 0$ and $\mathrm{f} 1$ are called respectively the initial and terminal maps. The second parameter of $\mathrm{H}$, also called the homotopy parameter, allows for a continuous deformation of f0 to f1 (Allgower and Georg, 1990). Two continuous functions $\mathrm{f} 0$ and $\mathrm{f} 1$ are said to be homotopic, denoted by $\mathrm{f} 0 \simeq \mathrm{f} 1$, if, and only if, there is a homotopy $\mathrm{H}$ taking f0 to $\mathrm{f} 1$. Being homotopic is an equivalence relation on the set $\mathrm{C}(\mathrm{X}, \mathrm{Y})$ of all continuous functions from $\mathrm{X}$ to $\mathrm{Y}$.

In this paper, we used homotopy to calibrate the range finder. The main idea is that assuming a linear model and a normal probability distribution function, we only assume that the calibration of the set of our range finder measurements with respect to the set of measurements of our total station can be done continuously, because there is no discontinuity in the n-dimensional space corresponding to the space of measurements performed using the range finder and the total station. Even though, not all real numbers are representable 
in a digital measurement device, we can assume that all the real numbers corresponding to measurements can be obtained physically, and it is just the fixed point notation used by the digital measurement device, that limits the set of representable real numbers to a discrete subset of the set of real numbers. Thus, we can compute the calibration of the range finder as a continuous function mapping our measurements obtained using our range finder to the measurements obtained using our total station.

The results of the linear homotopy continuation are presented in Figures 10 and Tables 6-8. One can calibrate the differences of horizontal angles observed with the rangefinder to the differences of horizontal angles observed with the theodolite. One can start from any point and point and assume that the measurement of the horizontal angle of that point by the rangefinder will not be changed by the calibration process. Without loose of generality, this point can be the first observed point. Now the idea for the calibration is that we are using each one of the intervals between measurements of horizontal angles made with the rangefinder, and we calibrate the new measurements of horizontal angles made by the rangefinder in each one of these intervals as a non-linear homotopy, where the homotopy parameter is the relative position of the measured horizontal angle in between the bounds of the enclosing interval of rangefinder horizontal angles. This homotopy calibration can be visualized as the continuous deformation of each sector (defined by the rangefinder horizontal angle intervals of room 1) of a plastic disk (corresponding to the old time theodolite graduated disk) to the corresponding sector of the total station's theodolite graduated disk. We used the intervals of total station horizontal angles of room 1 as reference intervals for all other horizontal angle measurements in rooms 1 and 10. In the remainder of the paper, "the homotopy parameter of a horisontal angle measurement" is equivalent to "the relative position of the horizontal angle measurement in the corresponding reference interval". We fitted a polynopmial of degree 5 through the 4 points whose $\mathrm{x}$-coordinates are the homotopy parameters of the horizontal angles measured by the rangefinder in room 10 and the corresponding homotopy parameters of the horizontal angles measured by the total station in room 10 and the points $(0,0)$ and $(1,1)$. We used this polynomial as the convex homotopy functlon that maps the uncalibrated homotopy paramter to the calibrated one.

The initial and terminal maps correspond respectively to the mappings between the uncalibrated and calibrated horizontal angles at the start point and the end point of the enclosing interval of horizontal angles measured by the range finder. We can observe that, contrary to the least squares calibration, the only limitation of this interval analysis and homotopy continuation based calibration is the precision of the fixed point arithmetic used by the computing device used for the calibration. The results shown in Table 8 proves that homotopies give the best results both in terms of RMSE and the $\mathrm{L}_{\infty}$ metric.

Table 6: Calibration of room 1 rangefinder horizontal angle measurements by homotopies.

\begin{tabular}{|l|l|l|l|l|l|}
\hline Point & $\begin{array}{l}\text { Rangefinder } \\
\text { horizontal angle }\end{array}$ & $\begin{array}{l}\text { Theodolite } \\
\text { horizontal } \\
\text { angle }\end{array}$ & $\begin{array}{l}\text { Calibrated rangefinder } \\
\text { horizontal angle }\end{array}$ & Theodolite internal angle & $\begin{array}{l}\text { Calibrated rangefinder } \\
\text { internal angle }\end{array}$ \\
\hline 1 & 268.9 & 0 & 268.9 & 67.745139 & 67.745139 \\
\hline 2 & 336.0 & 67.745139 & 336.645139 & 122.85028 & 122.85028 \\
\hline 3 & 99.6 & 190.595419 & 99.495417 & 65.881667 & 65.881667 \\
\hline 4 & 166.1 & 256.477086 & 165.377083 & 294.264583 & 294.264583 \\
\hline 5 & 98.5 & 190.741669 & 99.641667 & 169.258333 & 169.258333 \\
\hline
\end{tabular}

Table 7: Calibration of room 10 rangefinder horizontal angle measurements by homotopies

\begin{tabular}{|l|l|l|l|l|l|}
\hline Point & $\begin{array}{l}\text { Horizontal angle } \\
\text { rangefinder }\end{array}$ & $\begin{array}{l}\text { Horizontal angle } \\
\text { total station }\end{array}$ & Value of $\lambda$ & $\begin{array}{l}\text { Calibrated } \\
\text { horizontal } \\
\text { linear homotopy }\end{array}$ & $\begin{array}{l}\text { Calibrated horizontal angle } \\
\mathbf{0 . 9 3 2 5} \\
\text { non-linear homotopy }\end{array}$ \\
\hline 1 & 259.1 & 351 & 0.969504 & 259.753998 & 265.17 \\
\hline 2 & 355 & 86.3 & 0.198541 & 355.0770128 & 359.6978 \\
\hline 3 & 77.1 & 165.85 & 0.845307 & 77.50978924 & 81.0424 \\
\hline 4 & 180 & 274.92 & 0.220426 & 180.0977481 & 189.3224 \\
\hline
\end{tabular}

Table 8: Calibration of room 10 rangefinder horizontal angle measurements using total station horizontal angle measurements by homotopies and least squares. 


\begin{tabular}{|c|c|c|c|c|c|}
\hline Point & $\begin{array}{l}\text { Horizontal } \\
\text { angle } \\
\text { rangefinder }\end{array}$ & $\begin{array}{l}\text { Horizontal } \\
\text { angle total } \\
\text { station }\end{array}$ & $\begin{array}{l}\text { Calibrated } \\
\text { rangefinder } \\
\text { horizontal angle } \\
\text { (homotopy) }\end{array}$ & $\begin{array}{lr}\text { Calibrated } & \text { rangefinder } \\
\text { horizontal } & \text { angle } \\
(\text { polynomial } & \text { kernel, } \\
\text { degree=3) } & \end{array}$ & $\begin{array}{l}\text { Calibrated } \\
\text { rangefinder horizontal } \\
\text { angle (least squares) }\end{array}$ \\
\hline 1 & $\begin{array}{l}259.1 \\
\Delta 2-1=95.9\end{array}$ & $\begin{array}{l}351 \\
\Delta 2-1=95.3\end{array}$ & $\begin{array}{l}265.17 \\
\Delta 2-1=95.3\end{array}$ & $\begin{array}{l}17.8313 \\
\Delta 2-1=156.3488\end{array}$ & $\begin{array}{l}350.6725 \\
\Delta 2-1=95.7214\end{array}$ \\
\hline 2 & $\begin{array}{l}355 \\
\Delta 3-2=82.1\end{array}$ & $\begin{array}{l}86.3 \\
\Delta 3-2=79.55\end{array}$ & $\begin{array}{l}1.0650 \\
\Delta 3-2=79.55\end{array}$ & $\begin{array}{l}174.1801 \\
\Delta 3-2=\mathbf{2 5 0 . 1 6 7}\end{array}$ & $\begin{array}{l}86.3939 \\
\Delta 3-2=81.9472\end{array}$ \\
\hline 3 & $\begin{array}{l}77.1 \\
\Delta 4-3=102,9\end{array}$ & $\begin{array}{l}165.85 \\
\Delta 4-3=\mathbf{1 0 9 . 0 7}\end{array}$ & $\begin{array}{l}80.6150 \\
\Delta 4-3=\mathbf{1 0 9 . 0 7}\end{array}$ & $\begin{array}{l}64.3471 \\
\Delta 4-3=250.167\end{array}$ & $\begin{array}{l}168.3411 \\
\Delta 4-3=\mathbf{1 0 2 . 7 0 8 4}\end{array}$ \\
\hline 4 & $\begin{array}{l}180 \\
\Delta 1-4=79.1\end{array}$ & $\begin{array}{l}274.92 \\
\Delta 1-4=76.08\end{array}$ & $\begin{array}{c}189.6850 \\
\Delta 1-4=\mathbf{7 6 . 0 8}\end{array}$ & $\begin{array}{l}229.6545 \\
\Delta 1-4=148.1768\end{array}$ & $\begin{array}{l}271.0495 \\
\Delta 1-4=79.623\end{array}$ \\
\hline
\end{tabular}

\section{Conclusion}

The proposed research is to demonstrate the feasibility of interior survey ing for full 3D building modelling.. The main objective of this research was to propose a methodology for data capturing in indoor building environment. A rangefinder was compared to a high accurate surveying device (Leica scanstation C10) using weighted least squares, polynomial kernel and a novel technique based on interval analysis and homotopy continuation. In an indoor environment, the Trimble LaserAce 1000 showed inconsistencies within the uncertainty ranges claimed by the manufacturer for short distances in the horizontal angle.

\section{References}

Akhiezer, N. I., \& Glazman, I. M. (2013). Theory of linear operators in Hilbert space. Courier Corporation.

Allgower, E. L., K. Georg, (1990). Numerical continuation methods: an introduction. Springer-Verlag New York, Inc. New York, NY, USA.

Amato, E., Antonucci, G., Belnato, B. (2003). The three dimensional laser scanner system: the new frontier for surveying, The International Archives of the Photogrammetry, Remote Sensing and Spatial Information Sciences Vol. XXXIV-5/W12, 17-22

Browder, F. E., \& Petry shyn, W. V. (1967). Construction of fixed points of nonlinear mappings in Hilbert space.

Journal of Mathematical Analysis and Applications, 20(2), 197-228.

Deak, G., Curran, K., \& Condell, J. (2012). A survey of active and passive indoor localisation systems. Computer Communications, 35(16), 1939-1954.
Rangefinder data was calibrated by least square adjustment (absolute orientation) which shows a maximum error of 13 centimeters and a minimum error of 6 centimeters using the Leica scanstation $\mathrm{C} 10$ as a benchmark. By opposition, the combined interval analysis and homotopy continuation technique calibration obtained by continuous deformation of the function mapping the rangefinder measurements to the theodolite measurements allows a much better match, whose only limitation is the fixed point arithmetic of the computing device used to perform the computation. Results from polynomial kernel are not satisfactory (see Tables 8 ).

Donath, D., \& Thurow, T. (2007). Integrated architectural surveying and planning. Automation in Construction, 16(1), 19-27.

Dongzhen, J., Khoon, T., Zheng, Z., \& Qi, Z. (2009). Indoor 3D Modeling and Visualization with a 3D Terrestrial Laser Scanner. 3D Geo-Information Sciences, 247-255.

Gilliéron, P. Y., \& Merminod, B. (2003, October). Personal navigation system for indoor applications. In 11th IAIN world congress (pp.21-24).

Goetz, M., \& Zipf, A. (2011). Formal definition of a useradaptive and length-optimal routing graph for complex indoor environments. Geo-Spatial Information Science, 14(2), 119-128.

Haala, N., \& Kada, M., (2010). An update on automatic 3D building reconstruction. ISPRS Journal of Photogrammetry and Remote Sensing, 65(6), 570-580.

Habib, A.F., Zhai, R., Kim, C., (2010). Generation of complex polyhedral building models by integrating stereoaerial imagery and LiDAR data. Photogrammetric Engineering \& Remote Sensing 76 (5), 609-623. 
Li, Y., \& He, Z. (2008). 3D indoor navigation: a framework of combining BIM with 3D GIS. In 44th ISOCARP congress.

Jamali, A., Boguslawski, P., Duncan, E. E., Gold, C. M., \& Rahman, A. A. (2013). Rapid Indoor Data Acquisition for Ladm-Based 3d Cadastre Model. ISPRS Annals of Photogrammetry, Remote Sensing and Spatial Information Sciences, 1(1), 153-156.

Jamali, A., Abdul Rahman, A., Boguslawski, P., Kumar, P., \& M. Gold, C. (2015). An automated 3D modeling of topological indoor navigation network. GeoJournal.

Ramon Moore, R. K. E., Cloud, M. J. (2009). Introduction to interval analysis. SIAM (Society for Industrial and Applied Mathematics), Philadelphia.

Surmann, H., Nüchter, A., \& Hertzberg, J. (2003). An autonomous mobile robot with a $3 \mathrm{D}$ laser range finder for 3D exploration and digitalization of indoor environments. Robotics and Autonomous Systems, 45(3-4), 181-198.

Yuan, W., \& Schneider, M. (2010). iNav: An indoor navigation model supporting length-dependent optimal routing. In Geospatial Thinking (pp. 299-313). Springer Berlin Heidelberg. 